\title{
Cytotoxic necrotizing factor 1 hinders skeletal muscle differentiation in vitro by perturbing the activation/ deactivation balance of Rho GTPases
}

\author{
S Travaglione ${ }^{1,2,4}$, G Messina ${ }^{2,4}$, A Fabbri ${ }^{1}$, L Falzano ${ }^{1}$, \\ AM Giammarioli ${ }^{1}$, M Grossi ${ }^{2,5}$, S Rufini ${ }^{3,5}$ and C Fiorentini ${ }^{*, 1,5}$ \\ 1 Department of Drug Research and Evaluation, Istituto Superiore di Sanità, \\ Viale Regina 299, 00161 Rome, Italy \\ 2 Department of Cellular and Developmental Biology, University 'La Sapienza', \\ via dei Sardi 70, 00185 Rome, Italy \\ 3 University 'Tor Vergata', via della Ricerca Scientifica, 00133 Rome, Italy \\ ${ }^{4}$ S Travaglione and G Messina contributed equally \\ ${ }^{5} \mathrm{M}$ Grossi, S Rufini, C Fiorentini were principals investigators \\ * Corresponding author: C Fiorentini, Department of Drug Research and \\ Evaluation, Istituto Superiore di Sanità, Viale Regina 299, 00161 Rome, Italy. \\ Tel: + 390649903006; Fax: + 390649387100; \\ E-mail: carla.fiorentini@ iss.it
}

Received 02.8.04; accepted 17.9.04; published online 29.10.04 Edited by R Knight

\section{Abstract \\ The current knowledge assigns a crucial role to the Rho GTPases family (Rho, Rac, Cdc42) in the complex transductive pathway leading to skeletal muscle cell differentiation. Their exact function in myogenesis, however, remains largely undefined. The protein toxin CNF1 was herein employed as a tool to activate Rho, Rac and $\mathrm{Cdc} 42$ in the myogenic cell line $\mathrm{C2} 12$. We demonstrated that CNF1 impaired myogenesis by affecting the muscle regulatory factors MyoD and myogenin and the structural protein MHC expressions. This was principally driven by Rac/Cdc42 activation whereas Rho apparently controlled only the fusion process. More importantly, we proved that a controlled balance between Rho and $\mathrm{Rac} / \mathrm{Cdc} 42$ activation/deactivation state was crucial for the correct execution of the differentiation program, thus providing a novel view for the role of Rho GTPases in muscle cell differentiation. Also, the use of Rho hijacking toxins can represent a new strategy to pharmacologically influence the differentiative process. \\ Cell Death and Differentiation (2005) 12, 78-86. \\ doi:10.1038/sj.cdd.4401522 \\ Published online 29 October 2004}

Keywords: myoblast differentiation; CNF1; Rho GTPases; $\mathrm{C} 2 \mathrm{C} 12$

Abbreviations: MRFs, muscle-restricted regulatory factors; SRF, serum response factor; CNF1, cytotoxic necrotizing factor 1; GM, growth medium; DM, differentiation medium; MHC, myosin heavy chain

\section{Introduction}

Skeletal muscle cell differentiation is a multistep process that involves permanent withdrawal from the cell cycle, activation of muscle-specific genes, and fusion of differentiated myocytes in multinucleated myotubes. Terminal differentiation, both in vivo and in vitro, is regulated by the activity of musclerestricted regulatory factors (MRFs) belonging to the basic helix-loop-helix (bHLH) family, in concert with members of the E2A and myocyte enhancer factor 2 (MEF2) families. ${ }^{1,2}$ The four members of MRF family, MyoD, Myf5, myogenin and MRF4, activate transcription of target genes by binding to sequence-specific elements, present in muscle regulatory and structural gene enhancers. ${ }^{3}$ Besides governing transcription of muscle-specific genes, MRFs also control irreversible withdrawal from the cell cycle by interacting with key cell cycle regulators. ${ }^{4-6}$ Although several signal transduction pathways and protein-protein interactions regulating MRF expression and activity have been described, how these processes are integrated represents a major challenge in muscle differentiation research.

The evolutionary conserved small GTPases of Rho family, known primarily for their role in actin cytoskeleton organization, are involved in a large variety of biological functions, ${ }^{7}$ controlling nuclear signalling, gene transcription and cell differentiation, including skeletal muscle differentiation. The Rho GTPases, which belong to the Ras superfamily, are molecular switches that cycle between an inactive GDPbound and an active GTP-bound state. The Rho family encompasses the three subfamilies Rho, Rac and Cdc42 that differentially regulate the commitment to myogenesis. It is still under debate, however, how exactly each member of the Rho family influences the muscle differentiation and also which transductive pathway is regulated. Rho $\mathrm{A}$ has been reported to positively regulate MyoD expression and skeletal muscle cell differentiation, as it has been demonstrated to be required for serum response factor (SRF)-mediated activation of several muscle-specific gene promoters. ${ }^{8,9}$ Concerning Rac1 and Cdc42, their role on skeletal myogenesis appears to be controversial. On the one hand, expression of constitutively active forms of Rac1 and $\mathrm{Cdc} 42 \mathrm{Hs}$ inhibits myogenesis ${ }^{10,11}$ and they do that through the activation of JNK pathway. ${ }^{11}$ Also, Rac1 activation affects terminal differentiation by interfering with cell cycle withdrawal. ${ }^{12}$ On the other hand, inhibition of Rac1 and Cdc42Hs interferes with myogenesis, ${ }^{11,13}$ and this corresponds to a decrease in p38 MAPK activity. ${ }^{11}$ Moreover, Takano et al. ${ }^{13}$ reported that both RhoA and Cdc42/Rac1 subfamilies play a positive role in the differentiation of $\mathrm{C} 2 \mathrm{C} 12$ myoblasts. Indeed, expression of constitutively activated forms of Rho family members induced transcription of muscle-specific genes.

The Rho GTPases represent a target of growing interest for bacterial protein toxins, which in their turn represent invaluable tools for cell biology studies aimed at defining Rho functions. ${ }^{14}$ Herein we used a protein toxin from Escherichia coli, named cytotoxic necrotizing factor 1 (CNF1), which specifically activates Rho, Rac and Cdc42 by catalyzing their 
deamidation at a specific glutamine residue at the level of the switch 2 domain. ${ }^{15-17}$ Importantly, CNF1 can recognize the glutamine residue included in a specific amino-acidic sequence that is present only in members of the Rho family. ${ }^{17}$ Due to its peculiar activating property on Rho GTPases, CNF1 has already contributed to the investigation of relevant cellular processes, such as macropinocytosis, ${ }^{18}$ cell motility ${ }^{19}$ or NKmediated cytotoxicity. ${ }^{20}$

Therefore, in the present study, we have utilized CNF1 as a tool to modulate Rho GTPase activity in the mouse myogenic cell line $\mathrm{C} 2 \mathrm{C} 12$, and analyzed how it could influence muscle cell differentiation in relationship to the differential activation of the Rho family members as compared with the physiological process. The aim was to contribute to the definition of the puzzling role played by the Rho GTPases in muscle cells.

\section{Results}

\section{CNF1 hinders myotube formation in $\mathrm{C} 2 \mathrm{C} 12$ cells}

In this work, we employed the Rho GTPase-activating bacterial toxin CNF1 to approach the differentiation of C2C12 cells, the so far best characterized myogenic cell line. In the presence of a high concentration of serum, these cells proliferate as an undifferentiated population, while following serum deprivation they permanently withdraw from the cell cycle, undergo terminal differentiation and fuse into multinucleated myotubes. It is known that CNF1 causes an impressive rearrangement of the actin cytoskeleton in most cell lines studied so far, ${ }^{20,21}$ thus representing an extremely powerful tool to study those cellular functions that rely on actin network dynamics. Hence, our investigation started by analyzing the effects of CNF1 on the ultrastructure and actin cytoskeleton organization of $\mathrm{C} 2 \mathrm{C} 12$ cells, being the cytoskeleton architecture crucial during the muscle cell differentiation.

In order to investigate how myogenic cells morphologically respond to the toxin, $\mathrm{C} 2 \mathrm{C} 12$ cells were cultivated in growth medium (GM) for $24 \mathrm{~h}$ and then challenged with CNF1 (GM/ CNF1) for further $48 \mathrm{~h}$ or shifted in differentiation medium (DM) for $72 \mathrm{~h}$, in the presence (DM/CNF1) or absence (DM) of CNF1 (Figure 1). As shown by scanning electron microscopy (Figure 1a-d), CNF1 caused the enlargement and spreading of proliferating myoblasts (compare Figure 1a with Figure 1b), without altering the general cell morphology. In contrast, the presence of the toxin in DM impaired the phenotypic differentiation of myoblasts into myotubes (shown in Figure 1c), CNF1-treated cells showing a smooth myoblastlike surface, and appearing larger than control myoblasts (Figure 1d). As expected, such morphological alterations reflected profound modifications of the actin cytoskeletal architecture induced by CNF1 treatment (Figure 1e-h). In fact, whereas $\mathrm{C} 2 \mathrm{C} 12$ myoblasts (GM) were characterized by short stress fibres and membrane ruffles (Figure 1e), CNF1-treated myoblasts (GM/CNF1) displayed more evident stress fibres, but not ruffles (Figure 1f). When grown in $\mathrm{DM}$ for $72 \mathrm{~h}$, the majority of $\mathrm{C} 2 \mathrm{C} 12$ cells fused into multinucleated myotubes with the actin cytoskeleton arranged in long bundles crossing the myotube cell body, rather than

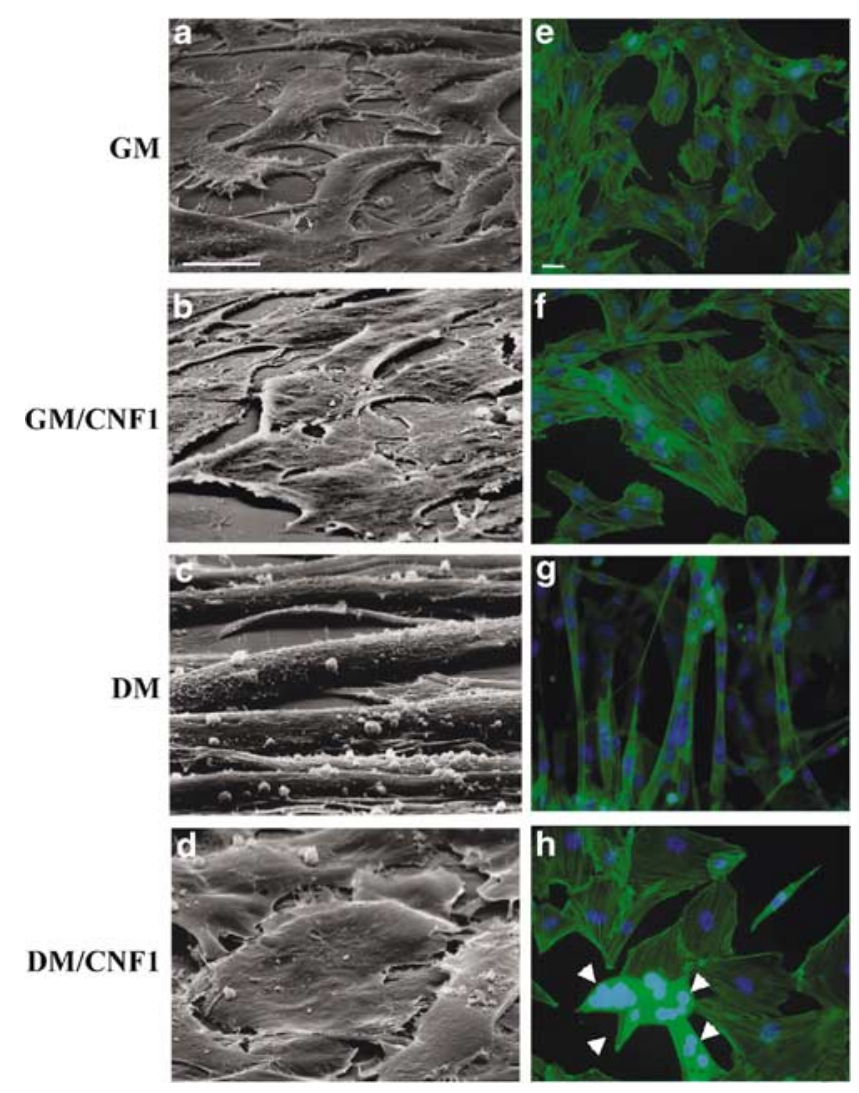

Figure 1 CNF1 impairs myotube formation and reorganizes the actin cytoskeleton in $\mathrm{C} 2 \mathrm{C} 12$ cells. $\mathrm{C} 2 \mathrm{C} 12$ cells were cultivated in growth medium (GM) (a, e) for $24 \mathrm{~h}$ and then challenged with CNF1 (GM/CNF1) (b, f) for further $48 \mathrm{~h}$ or shifted in differentiation medium (DM) for $72 \mathrm{~h}$, in the presence (DM/ CNF1) (d, h) or absence (DM) (c, g) of CNF1. (a-d) Scanning electron microscopy (SEM) analysis shows that CNF1 causes the enlargement and spreading of proliferating myoblasts (compare a with $\mathbf{b}$ ), without altering the general cell morphology. While cells maintained in DM (c) for $72 \mathrm{~h}$ fuse to form multinucleated myotubes, CNF1-treated cells (d) are unable to form myotubes and show a smooth myoblast-like surface phenotype, although appearing larger than control myoblasts (a). (e-h) Fluorescence microscopy analysis of $\mathrm{C} 2 \mathrm{C} 12$ cells co-stained with fluoresceine-conjugated-phalloidin, to define F-actin organization, and with the nuclear dye DAPI. Note that CNF1-treated myoblasts (f) show more evident stress fibres than control cells (e). In DM (g), cells form multinucleated myotubes with actin organized in long and thick bundles. When CNF1 is added simultaneously to the shift in DM (h), most cells appears mononucleated and with prominent stress fibres. Many collapsed myotubes (arrows) intensively stained with FITC-phalloidin are detectable. In (e-h), individual pictures of the same field, taken with a DC camera, were merged using a LEICA Microsystems Imaging Equipment. Bar = (a-d) $40 \mu \mathrm{m}$; (e-h) $20 \mu \mathrm{m}$

in stress fibres (Figure 1g). The addition of CNF1 to the cells since the beginning of the incubation time in DM (DM/CNF1) prevented the morphological differentiation of myoblasts in myotubes. Cells, indeed, appeared mostly mononucleated with the actin cytoskeleton organized in stress fibres, resembling cultures in GM conditions (Figure 1h).

The evidence presented clearly demonstrates that CNF1 is able to perturb the physiological actin cytoskeleton organization in myogenic cells, as occurs in other cell types, ${ }^{20,21}$ and to dramatically impair myotube formation upon differentiative stimuli. 


\section{CNF1 treatment interferes with muscle-specific gene expression in $\mathrm{C} 2 \mathrm{C} 12$ cells}

Loss of competence of CNF1-treated C2C12 to form multinucleated myotubes would not necessarily correspond to lack of myogenic biochemical differentiation. Indeed, examples of biochemical differentiation without fusion have been reported for Myc-transformed $\mathrm{C} 2 \mathrm{C} 12$ cells and MRF-converted NIH3T3 cells. ${ }^{22,23}$ Based on this notion, we wondered whether, behind the inability to form multinucleated myotubes, CNF1-treated $\mathrm{C} 2 \mathrm{C} 12$ cells were still able to accomplish the differentiative program and express skeletal muscle-associated markers when induced to differentiate. Hence, we first investigated the expression of skeletal muscle myosin heavy chain (MHC), performing a qualitative analysis by indirect immunofluorescence. Figure $2 a$ shows that $\mathrm{C} 2 \mathrm{C} 12$ cells grown in DM for $72 \mathrm{~h}$ underwent terminal differentiation, fused into multinucleated myotubes and accumulated $\mathrm{MHC}$ with high efficiency (DM), while MHC expression was severely reduced by the presence of CNF1 (DM/CNF1). In this last condition, the majority of MHC-expressing cells was mononucleated. The latter phenotype was further evidenced by the fusion index evaluation of $\mathrm{C} 2 \mathrm{C} 12$ cells maintained in DM or DM plus CNF1 (Figure 2b). In fact, untreated cells displayed a considerably high fusion ability (more than 60\%) while the

a

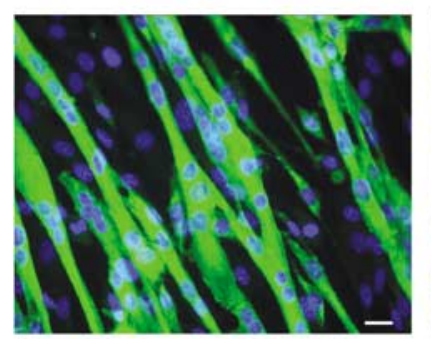

b

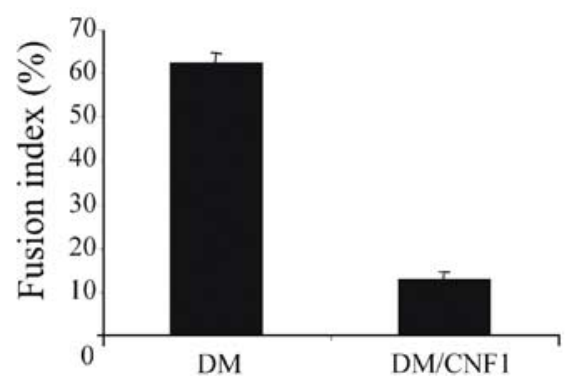

Figure 2 CNF1 dramatically decreases the ability of $\mathrm{C} 2 \mathrm{C} 12$ cells to fuse into MHC-positive myotubes. (a) Immunofluorescence analysis of skeletal myosin heavy chain (MHC), the typical marker of terminally differentiated muscle cells. MHC protein is highly expressed in C2C12 cells grown in DM for $72 \mathrm{~h}$ and virtually absent in most cells in CNF1-treated cultures, although still detectable in the rare polycarions (arrows). (b) Graph showing the fusion index of $\mathrm{C} 2 \mathrm{C} 12$ cells grown in $\mathrm{DM}$ for $72 \mathrm{~h}$ in the presence (DM/CNF1) or in the absence (DM) of CNF1. Cells were stained for $\mathrm{MHC}$ and the fusion index was defined as the percentage of nuclei belonging to MHC-positive cells with three or more nuclei. Note that CNF1 dramatically reduces the ability of cells to fuse into multinucleated myotubes. The values reported in the graph are the means \pm standard deviations (S.D.) from three separate experiments performed in duplicate. In (a), individual pictures of the same field, taken with a DC camera, were merged using a LEICA Microsystems Imaging Equipment. Bar $=20 \mu \mathrm{m}$ fusion index of $\mathrm{C} 2 \mathrm{C} 12$ cells under differentiation conditions in the presence of CNF1 never exceeded 15\%. Furthermore, such a minor percentage of multinucleated cells could be ascribed to the presence of polycarions (arrows in Figure 2a) instead of true myotubes.

Western blot analysis confirmed the CNF1 capacity of lessening the expression of MHC (Figure 3a), a decrease due to the interference of the toxin with the specific mRNA accumulation, as demonstrated by data from Northern blot experiments (Figure $3 b$ ). It is largely documented that the expression of many myogenic differentiation-associated

a
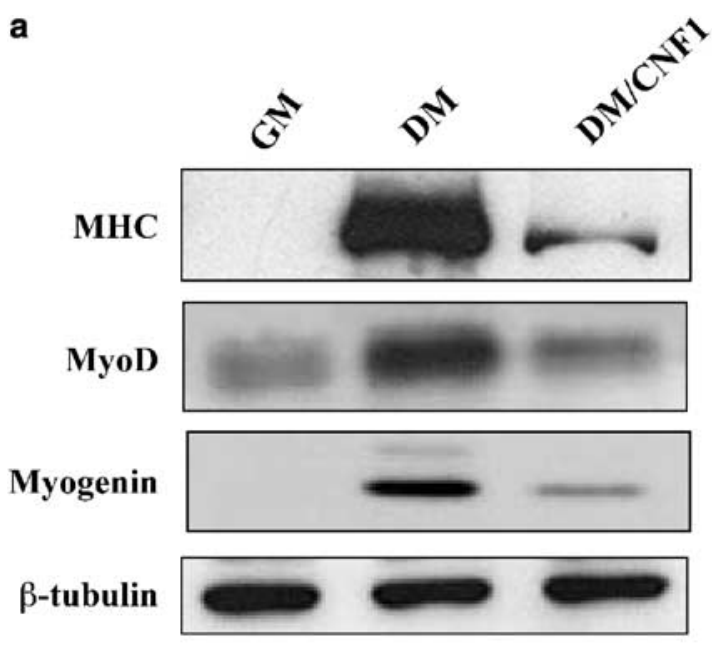

b

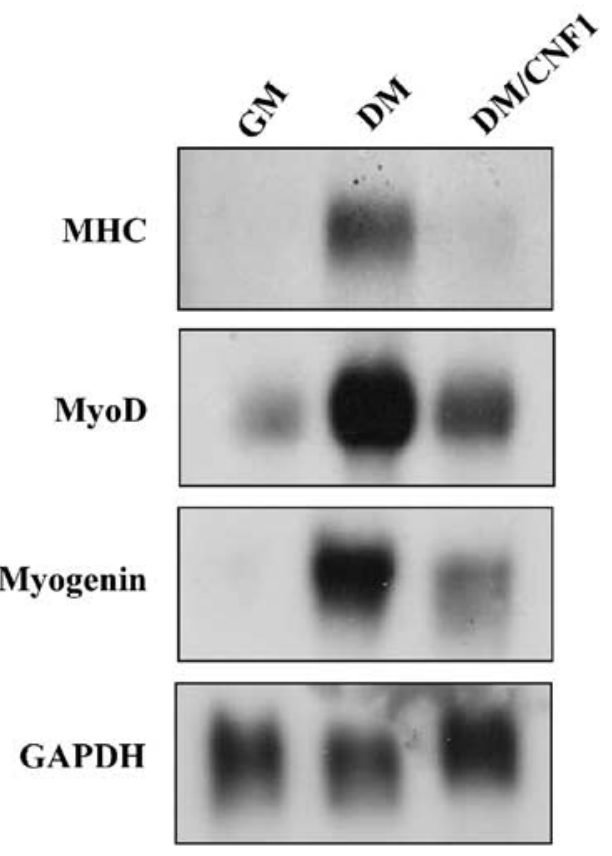

Figure 3 CNF1 downregulates the expression of $\mathrm{MHC}$ and of the myogenic regulatory factors (MRFs) MyoD and Myogenin. (a) Western blot analysis of $\mathrm{C} 2 \mathrm{C} 12$ cells grown in DM for $72 \mathrm{~h}$ in the presence or in the absence of CNF1. The blots clearly show the ability of CNF1 to interfere with the expression of MHC, MyoD and myogenin. (b) Northern blot analysis of $\mathrm{C} 2 \mathrm{C} 12$ cells grown in the same conditions as in (a), showing a negative effect of CNF1 on the accumulation of $\mathrm{MHC}$, MyoD and myogenin mRNAs. Equal protein (a) and mRNA (b) loading was confirmed by detecting $\beta$-tubulin and GAPDH, respectively 
genes, including $\mathrm{MHC}$, is regulated by the activity of musclerestricted transcription factors belonging to the MyoD family, including MyoD, Myf5, Myogenin and MRF4. ${ }^{2}$ In turn, the expression of myogenin is directly induced by MyoD at the onset of muscle differentiation. ${ }^{24}$ On this notion, we wondered whether the impairment of $\mathrm{C} 2 \mathrm{C} 12$ myoblasts differentiation by CNF1 could reflect a defect in the expression of muscle regulatory factors (MRFs). For this purpose, the accumulation of MyoD and myogenin proteins at $72 \mathrm{~h}$ in DM was analyzed by Western blot. Data presented in Figure 3a clearly showed that the presence of CNF1 in the differentiative medium considerably reduced the expression of MyoD protein. As expected, also myogenin was downregulated, being this gene a direct target of MyoD trans-activating function. As for $\mathrm{MHC}$ expression, Northern blot experiments indicated that the downregulation of MyoD and Myogenin was a consequence of the marked reduction in the respective mRNA levels (Figure 3b).

Taken together, these results highlight that the dramatic effects exerted by CNF1 on the morphological differentiation of $\mathrm{C} 2 \mathrm{C} 12$ cells are paralleled by an interference with the biochemical differentiation.

\section{CNF1 induces a sustained activation of RhoA, Rac1 and Cdc42 GTPases in C2C12 cells}

It is widely reported that the characterizing function of CNF1 is to permanently activate Rho, Rac and Cdc42 GTPases in all cell systems where its effect has been studied, but the timing and level of activation of distinct members of Rho GTPase family differ depending on the cell type. ${ }^{19,25,26}$ Furthermore, although many data have been accumulated on the effects of activated or dominant-negative forms of such GTPases on the skeletal muscle differentiation in vitro, ${ }^{8-13,27}$ very few is known about the activation state and dynamics of RhoA, Rac1 and Cdc42 during myogenic differentiation process. Hence, in order to establish a relationship between the lack of differentiation potential in CNF1-treated $\mathrm{C} 2 \mathrm{C} 12$ cells and the activation of distinct member(s) of Rho GTPases family targeted by CNF1, we monitored the activity of Rho GTPases during the differentiative process, either in control $\mathrm{C} 2 \mathrm{C} 12$ cells or in CNF1-treated cultures. For this purpose, cells were cultured in DM or in DM plus CNF1 for different period lengths (3, 24 and $72 \mathrm{~h}$ ) and, at each time point, the amount of GTP. bound RhoA, Rac1 and Cdc42 GTPases was detected by a pull-down assay (see Materials and methods). The results obtained are reported in Figure 4. The immmunoblots (line 1) were analyzed by densitometry (see Materials and methods) and normalized as a function of the total proteins loaded in the assay (histograms in line 2).

As shown in Figure 4a, while a very small amount of GTPbound RhoA was detectable in proliferating myoblasts, the active form of the protein virtually disappeared in differentiating cells (DM 3 and $24 \mathrm{~h}$ ) and returned to the level observed in myoblasts, in differentiated myotubes (DM $72 \mathrm{~h}$ ). This would suggest the necessity of a 'switch off' of the RhoA protein during the first steps of the differentiative process. CNF1 was able to induce a dramatic and time-dependent activation of the protein, being the amount of RhoA-GTP significantly and progressively augmented starting from the first hours until $72 \mathrm{~h}$ of culture in the differentiative medium (Figure 4a). Rac1 GTPase (Figure 4b) was active in proliferating C2C12 cells (GM) and in the first $24 \mathrm{~h}$ of culture in DM (DM 3 and $24 \mathrm{~h}$ ), while the amount of Rac1-GTP dramatically decreased after $72 \mathrm{~h}$ in DM, when cultures were fully differentiated. This kinetics suggests that Rac1 GTPase should be inactivated in order to achieve the terminal differentiation of myoblasts in myotubes. In cells grown in DM, CNF1 induced a timedependent increase and sustained activation of the Rac1 GTPase, being the protein still active following $72 \mathrm{~h}$ of culture in DM. A small amount of Cdc42-GTP (Figure 4c) was already present in proliferating myoblasts. When cells were shifted in DM, the activation level of this GTPase significantly increased and remained elevated until $72 \mathrm{~h}$. CNF1 was not able to further increase the levels of Cdc42 activated form during the first $24 \mathrm{~h}$ of culture in DM, while, following $72 \mathrm{~h}$, the amount of activated Cdc42 in DM/CNF1 was dramatically enhanced with respect to untreated $\mathrm{C} 2 \mathrm{C} 12$ cells (Figure 4c).

The histograms reported in line 3 of Figure 4 illustrate the difference between CNF1-induced Rho GTPases activation and the activity of the same proteins throughout the differentiation process of $\mathrm{C} 2 \mathrm{C} 12$ cells, and underline the diverse activation kinetics imposed by CNF1. This analysis demonstrated that: (A) RhoA was activated by CNF1 since the first hours of incubation with the toxin (3h); (B) Rac1 activation began following $24 \mathrm{~h}$ of CNF1-exposure while $(\mathrm{C})$ an increase of CNF1-activated Cdc42 was observable only at $72 \mathrm{~h}$. From this additional data processing it appears that the activity of CNF1, in C2C12 cells maintained in DM, was exerted mainly on the RhoA GTPase, as CNF1 induced a prompt and strong relative activation of the protein, which, instead, seems to be inactivated in response to differentiation stimuli. On the other hand, the effects of CNF1 on Rac1 and, even more, on Cdc42, became evident only much later, when $\mathrm{C} 2 \mathrm{C} 12$ were expected to be fully committed.

\section{Time-dependent modulation of muscle markers expression by CNF1}

On the basis of the above-described results, we decided to investigate muscle-specific gene expression kinetics in both control and CNF1-treated C2C12 cells in relationship with the Rho GTPase activation state at the different time points. For this purpose, we performed a time course study on the expression of $\mathrm{MHC}, \mathrm{MyoD}$ and Myogenin in $\mathrm{C} 2 \mathrm{C} 12$ cells grown in DM for 3, 24 and $72 \mathrm{~h}$, in the presence or absence of CNF1. The Western blot analysis in Figure 5 clearly shows that the MHC protein was still lacking after $24 \mathrm{~h}$ of challenge with CNF1 and its accumulation after $72 \mathrm{~h}$ was significantly lower than in untreated $\mathrm{C} 2 \mathrm{C} 12$. By contrast, it appeared also evident that CNF1 was able to induce a significant downregulation of MyoD and Myogenin proteins only following $72 \mathrm{~h}$ of incubation in DM. Interestingly, in the first $24 \mathrm{~h}$ of differentiation, only $\mathrm{MHC}$ was differently expressed in control and CNF1-treated cells, suggesting a prominent interference of $\mathrm{CNF} 1$ with the structural protein accumulation rather than muscle regulatory factors. 

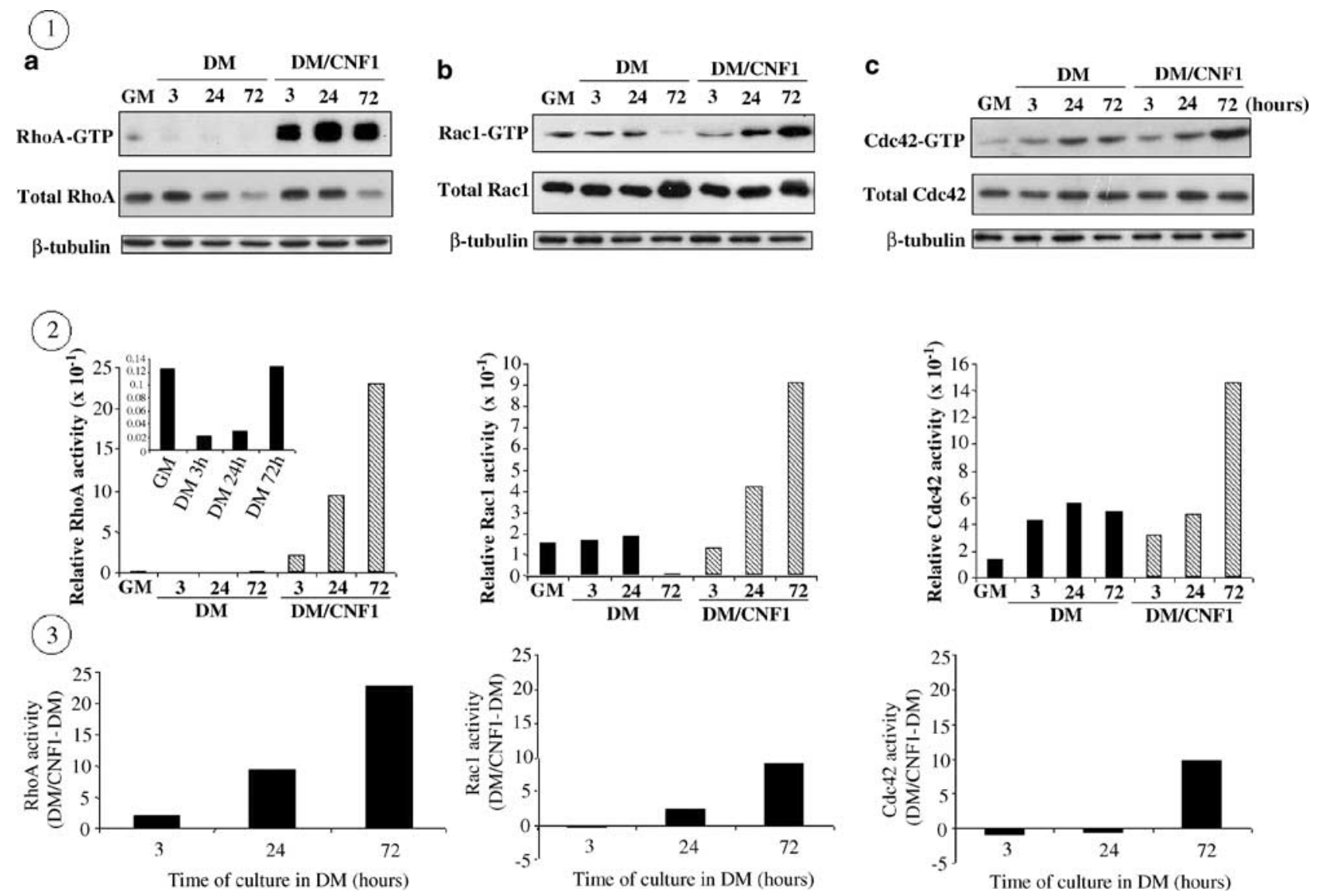

Figure 4 Activation kinetics of RhoA, Rac1 and Cdc42 GTPases. C2C12 cells were grown in GM for $24 \mathrm{~h}$ and then shifted in DM or in DM plus CNF1. At the indicated time points, cells were lysed and the active forms of RhoA, Rac1 and Cdc42 present in each sample were detected by a Pull Down assay, as described in Materials and Methods. (Line 1) Immunoblots showing the kinetics of RhoA (a), Rac1 (b) and Cdc42 (c) activation (upper panels) in untreated and CNF1-treated C2C12 cells. The total amount of RhoA, Rac1 and Cdc42 proteins loaded in the assay was determined by Western blot (lower panels). Equal protein loading was confirmed by detecting $\beta$ tubulin. (Line 2) The results in line 1 were analyzed by densitometry, as described in Materials and Methods. The histograms represent the GTPase activity normalized for the amount of total protein loaded. The inset in (a) shows the first four columns of the histogram reported in a smaller scale. (Line 3) Graphs showing the differences in the activation levels of RhoA, Rac1 and Cdc42 between CNF1-treated and control cells, at 3, 24 and $72 \mathrm{~h}$ in DM. Data are representative of three independent experiments

\section{The ability of CNF1 to impair muscle cell differentiation is dependent on the activation of Rho GTPases}

In order to verify whether the ability of CNF1 to impair muscle cell differentiation required the activation of the Rho GTPases, $\mathrm{C} 2 \mathrm{C} 12$ cells shifted in DM were pre-exposed to the Rhoinhibiting toxin $\mathrm{B}(\mathrm{CdB})$ from Clostridium difficile and exoenzyme $\mathrm{C} 3$ from $C$. botulinum, before adding CNF1. $\mathrm{CdB}$ acts by covalently linking a UDP-glucose at Threonine 35/37 of Rho and Rac/Cdc42, respectively, ${ }^{28}$ while C3 acts by ADP-ribosylating Rho A, B, C proteins of the Rho subfamily at Asn $41 .{ }^{29} \mathrm{C} 2 \mathrm{C} 12$ cells, shifted in DM, were: (i) challenged with the inhibiting toxins alone in the absence of CNF1, for $72 \mathrm{~h}$ or (ii) pretreated for $3 \mathrm{~h}$ with either $\mathrm{C} 3$ or $\mathrm{CdB}$, before addition of CNF1 for further $72 \mathrm{~h}$. Data from Western blot analysis, illustrated in Figure $6 \mathrm{a}$, clearly evidenced that, although neither $\mathrm{CdB}$ nor $\mathrm{C} 3$ alone significantly interfered with the ability of $\mathrm{C} 2 \mathrm{C} 12$ cells to express $\mathrm{MHC}$, the effects of CNF1 on
MHC expression was considerably counteracted by $\mathrm{CdB}$ but not by C3 pretreatments. This points out at Rac/Cdc42 (but not Rho) activation as a major player in the CNF1-induced impairment of skeletal muscle terminal differentiation. Inhibition of the Rho subfamily by $\mathrm{C} 3$, although did not interfere with $\mathrm{MHC}$ expression, however, rendered $\mathrm{C} 2 \mathrm{C} 12$ cells unable to fuse into multinucleated myotubes. In fact, the majority of the thin and elongated MHC-positive cells shown in Figure 6b contained only one or two nuclei. This last result suggests that Rho protein is dispensable for the biochemical differentiation of $\mathrm{C} 2 \mathrm{C} 12$ cells but is required in the fusion process. The small amount of Rho-GTP detectable by pull down assays at $72 \mathrm{~h}$ in DM (Figure 4a) is conceivably critical for this last phase of skeletal muscle differentiation.

\section{Discussion}

In the current article, we provide a novel view on the role of Rho GTPases in muscle cell differentiation, by identifying in 


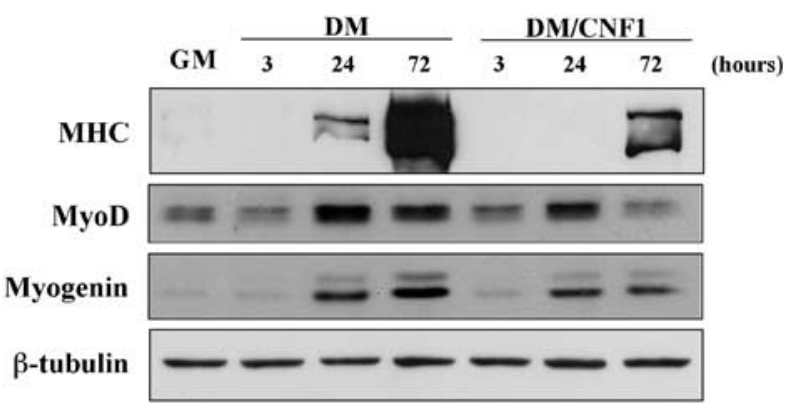

Figure 5 CNF1 affects MRFs and MHC expression with a diverse kinetics. C2C12 cells were grown in GM for $24 \mathrm{~h}$ and then shifted in DM or in DM plus CNF1. At the indicated time points, cells were lysed and the expression of MHC, $\mathrm{MyoD}$ and myogenin was analyzed by Western blot. The blots clearly show that CNF1 perturbs the expression of the MRFs (MyoD and Myogenin) only following $72 \mathrm{~h}$ of incubation, whereas totally prevents $\mathrm{MHC}$ expression at $24 \mathrm{~h}$, when $\mathrm{MHC}$ appears in untreated $\mathrm{C} 2 \mathrm{C} 12$. After $72 \mathrm{~h}$, only very low levels of $\mathrm{MHC}$ are detectable in CNF1-treated cultures although dramatically diminished if compared with control $\mathrm{C} 2 \mathrm{C} 12$. Equal proteins loading was confirmed by detecting $\beta$-tubulin

the Rho activation/deactivation balance one of the crucial aspects that guide the skeletal differentiation program. Also importantly, we propose a new strategy to influence the myogenic process, in a pharmacologically way, by means of well-characterized protein toxins that hijack the Rho proteins.

On the whole, our results demonstrate the existence of an antagonism between Rho and Rac/Cdc42 activities during C2C12 cell differentiation. It was evident indeed a balance between the two subfamilies Rho and Rac/Cdc42, the level of Rho-GTP mirroring first Cdc42 and then Rac. After $24 \mathrm{~h}$ in DM, Cdc42-GTP level significantly increased while Rho-GTP decreased, all this apparently being correlated with the appreciably increased expression of MyoD and appearance of myogenin. At $72 \mathrm{~h}$, when $\mathrm{C} 2 \mathrm{C} 12$ cells achieved fully differentiated state, levels of Cdc42-GTP remained high, while Rac-GTP dramatically decreased and Rho-GTP increased. Such changes in the ratio between activated Rho GTPases subfamilies corresponded to a further increase of myogenin expression and very high levels of $\mathrm{MHC}$ protein in multinucleated myotubes. These findings suggest that Cdc42/ Rho balance would control the early events of the differentiative cascade whereas Rac/Rho balance plays a part in the latest. Pioneering studies in serum-starved Swiss 3T3 fibroblasts have shown a hierarchical, linear cascade of activation linking Cdc42 signalling to activation of Rac and then Rho. ${ }^{30,31}$ The current wisdom, however, is that the different Rho GTPase pathways antagonize rather than activate each other. Indeed, Rac and Cdc42 produce different cellular responses and their activity has been reported as antagonistic to that of Rho in different cell types. In fibroblasts, activation of Rac has been shown to downregulate Rho activity $^{32}$ and, where Cdc42 and Rac promote membrane protrusions, Rho promotes membrane retraction through contractile actin and myosin filaments. ${ }^{7}$ In neuronal cells, Cdc42 and Rac are positive regulators of neurite outgrowth, whereas Rho inhibits neurite extension. ${ }^{33}$ Not only Rho- and Rac/Cdc42-induced phenotypes appear mutually exclusive, a

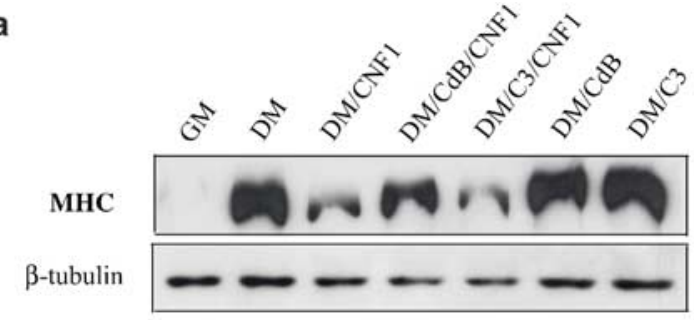

b
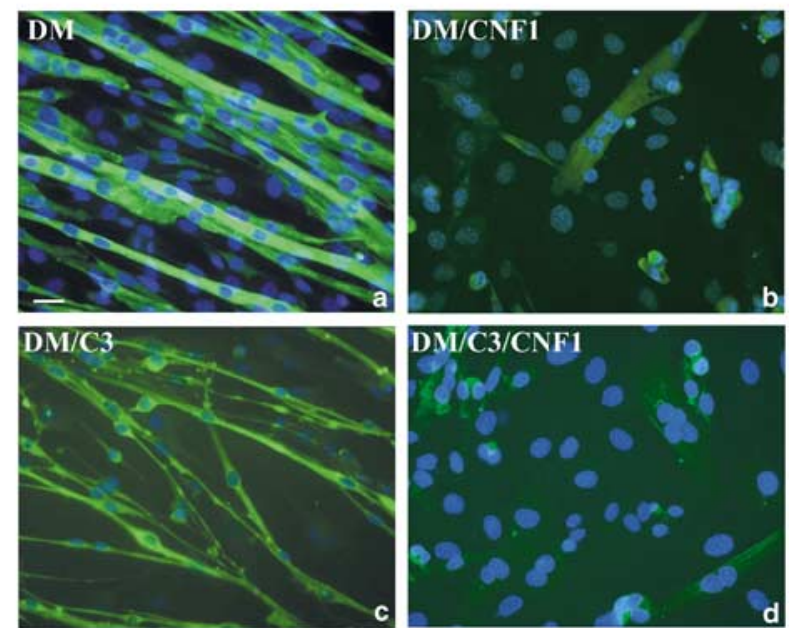

Figure 6 The effects of CNF1 on muscle cell differentiation are strictly dependent on the activation of Rho GTPases. At $24 \mathrm{~h}$ after seeding, $\mathrm{C} 2 \mathrm{C} 12$ cells were: (i) shifted in DM (DM); (ii) shifted in DM plus CNF1 (DM/CNF1); (iii) preexposed in DM for $3 \mathrm{~h}$ to $\mathrm{CdB}$ or $\mathrm{C} 3$ before addition of CNF1 (DM/CdB/CNF1 and $\mathrm{DM} / \mathrm{C} 3 / \mathrm{CNF} 1$, respectively) or (iv) treated with $\mathrm{CdB}(\mathrm{DM} / \mathrm{CdB})$ or $\mathrm{C} 3(\mathrm{DM} / \mathrm{C} 3)$ alone in DM. Following $72 \mathrm{~h}$, cells were processed for MHC detection either by Western blot (a) or by immunofluorescence (b). Pretreatment with $\mathrm{CdB}$, but not with $\mathrm{C} 3$, is able to partially counteract the effects of CNF1 on MHC accumulation. Note that C3-treated cells (DM/C3) are still able to express MHC (a) but fail to fuse into multinucleated myotubes, being the majority of cells in this sample mononucleated or binucleated (b). In (a), equal proteins loading was confirmed by detecting $\beta$-tubulin. In (b), individual pictures of the same field, taken with a DC camera, were merged using a LEICA Microsystems Imaging Equipment. $\mathrm{Bar}=20 \mu \mathrm{m}$

but also Rho- and Rac/Cdc42-mediated pathways regulate each other. Such a phenotypic antagonism reflects their activation state in various cell types, where the levels of active $\mathrm{Rac} / \mathrm{Cdc} 42$ are inversely correlated to the levels of active Rho. This is true, for example, in epithelial cells that are growing or undergoing cadherin-dependent cell-cell contact formation $^{32,34}$ and in fibroblasts during spreading onto fibronectin. ${ }^{35}$ Of importance, regulatory pathways can target either the switch mechanism ${ }^{36}$ or a GTPase effector pathway ${ }^{32,37}$ with a similar outcome. Interestingly, a well-defined temporal activation/deactivation of Rho proteins in response to a single stimulus has been reported during the clustering of acetylcholine receptors (Ach-R), induced by agrin in muscle cells. ${ }^{38}$ In this case, a transient activation of Rac induces a first Ach-R localization, while the final clustering of receptors is controlled by Rho, and needs a deactivation of Rac. Thus, we herein hypothesize that the maintenance of a dynamic balance between Rho and Rac/Cdc42 activities is crucial for the occurrence of the correct muscle cell differentiation. 
The herein described overall effect of CNF1 on the myogenic process supported the previously reported notion of a general negative regulation of Rac1/Cdc42 on myogenesis. ${ }^{10-12,39}$ The challenge with CNF1 also indicates that the Rho GTPases must be activated several folds with respect to the basal levels to exert their negative control. ${ }^{10}$ In fact, we have observed a discrete level of activated Rac1/Cdc42 during the first $24 \mathrm{~h}$ after differentiation induction, suggesting that Rac/Cdc42 activation is consistent with, and probably required for, early steps of skeletal muscle differentiation. This assumption is also supported by previous reports indicating that dominant-negative forms of Rac1 and Cdc42 cause the complete failure of terminal myogenic differentiation. ${ }^{11,13,40}$ In this paper, we also demonstrated that CNF1 induced a temporally different and defined activation kinetics of RhoA, Rac1 and $\mathrm{Cdc} 42$, in $\mathrm{C} 2 \mathrm{C} 12$ muscle cells undergoing differentiation. Indeed, it is worth noting that the timing of activation and the type of Rho GTPases involved in the cell response to CNF1 varies depending on the cell type. In bladder cells, CNF1-induced activation of Rho GTPases is a transient phenomenon, maximal for Rac. ${ }^{19}$ The activation of Rac correlates with the increase of susceptibility of deamidated form to ubiquitin/proteasome-mediated degradation and is followed by an impressive migratory activity of cells. ${ }^{19}$ On the other hand, in epithelial cells from larinx, we have demonstrated that the Rac-GTP, whose level is augmented by $\mathrm{CNF} 1$, acts as a pivotal molecule in the activation of the transcription factor nuclear factor $-\kappa \mathrm{B}(\mathrm{NF}-\kappa \mathrm{B}) .{ }^{41}$ In endothelial cells, CNF1 stimulation induced myosin light chain (MLC) phosphorylation that was due to Rho but not Rac or Cdc42 activity. ${ }^{25}$ In $\mathrm{C} 2 \mathrm{C} 12$ cells undergoing differentiation, in the first $24 \mathrm{~h}, \mathrm{CNF} 1$ augmented nearly 10-fold the level of RhoA-GTP and two-fold Rac1-GTP without changing Cdc42-GTP level. At this time, CNF1 was unable to influence MyoD and myogenin expression although interfered with $\mathrm{MHC}$ accumulation. MyoD and myogenin expression diminished only after $72 \mathrm{~h}$ of CNF1 exposure, when both Rac and Cdc42 activation levels were dramatically increased. All this further supports our hypothesis of a connection existing between Cdc42 activation levels and MyoD/myogenin expression. Rho-GTP was also further increased by CNF1 at $72 \mathrm{~h}$, although this appeared irrelevant for MRFs expression, as it already occurred at $24 \mathrm{~h}$ when both MyoD and Myogenin levels were comparable to those present in untreated cultures.

Consistent with the last finding, the experiments carried out with the Rho-inhibiting C3 clearly showed a minor role (if any) of RhoA in regulating the expression of biochemical differentiation markers. Our observations are conflicting with data reported by other authors, which envisage a positive role for

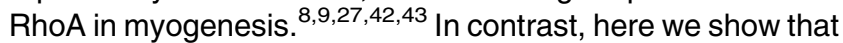
activated Rho subfamily was detectable only in proliferating C2C12 cells and in fully differentiated myotubes (72h DM); inhibition of Rho by C3 transferase had no effect on expression of structural muscle markers, indicating that the pathways governing biochemical differentiation do not require Rho activity. On the contrary, activated Rho appears to have a prominent role in the fusion process, as C3-treated $\mathrm{C} 2 \mathrm{C} 12$ myocytes failed to fuse into multinucleated myotubes. The different effects of $\mathrm{C} 3$ on myoblast fusion and $\mathrm{MHC}$ expression indicate the existence of a (at last) bifurcating pathway acting on the myogenic program. Interestingly, in contrast with the dramatic effects on the fusion process caused by C3induced Rho inhibition, the simultaneous inhibition of the whole Rho family (Rho/Rac/Cdc42) provoked by CdB did not seemingly act on the fusion process (data not shown). This apparent discrepancy can be explained with and support also our assumption that Rho somehow can balance the Rac/ Cdc42 activity during the myogenic differentiation. In fact, $\mathrm{CdB}$ was able to counteract the drop in $\mathrm{MHC}$ content caused by $\mathrm{CNF} 1$ in differentiating myocytes, clearly indicating that the $\mathrm{MHC}$ expression was strictly dependent on the activation state of the Rho proteins.

In our view, the discrepancy existing among statements from different authors on the role of Rho GTPases in muscle cell differentiation likely depends on transfection strategies widely used by the researchers involved in this field. For instance, cell-transfection using different mutants of members of Rho family could interfere with different downstream pathways, as demonstrated in cells other than myoblasts. ${ }^{44,45}$ Moreover, a different level of Rho activation caused by diverse transfection approaches can lead to a completely different response. ${ }^{10,13}$ The main advantage of our strategy that entails the use of protein toxins, with respect to transfection assays, resides in the ability of the toxins we have dealt with to enter the whole-cell population and to allow, at the doses used, the survival and activity of the 'touched' cells for a period of time longer than that of transfected cells. Besides, by means of toxins we have had the possibility to define the temporal occurrence in which a member of the Rho family plays its role in muscle differentiation, a question that transfection experiments have so far left unanswered. Hence, by CNF1, we provide new insights in understanding the puzzling role played by different members of the Rho family during myogenesis. Also, our results demonstrate that a clearcut activation/ deactivation balance of Rho family members is mandatory to correctly accomplish terminal differentiation in $\mathrm{C} 2 \mathrm{C} 12$ cells.

As a long-term goal, we hypothesize the possibility to use a natural product, such as a protein toxin, to modulate also in vivo muscle cell differentiation, a process that is fundamental for human health.

\section{Materials and Methods}

\section{Cells and bacterial toxins}

$\mathrm{C} 2 \mathrm{C} 12$ cells, a myogenic cell line derived from mouse muscle satellite cells, were grown in Dulbecco's modified Eagle's medium (DMEM) (GIBCO) supplemented with 10\% fetal bovine serum (FBS), $2 \mathrm{mM}$ glutamine, $0.05 \mathrm{IU} / \mathrm{ml}$ penicillin and $0.05 \mathrm{IU} / \mathrm{ml}$ streptomycin (GM) in a humidified atmosphere of $5 \% \mathrm{CO}_{2}$ at $37^{\circ} \mathrm{C}$. For all experiments, cells were seeded in GM at a density of $2 \times 10^{4}$ cells $/ \mathrm{cm}^{2}$. Terminal differentiation was induced, $24 \mathrm{~h}$ after seeding, by shifting $\mathrm{C} 2 \mathrm{C} 12$ cells into DM (DMEM supplemented with $0.5 \% \mathrm{FBS}$ ).

CNF1 was purified as previously described ${ }^{46}$ from 392 ISS E. coli strain (kindly provided by V Falbo, ISS, Rome, Italy). Clostridium difficile toxin B $(\mathrm{CdB})$ was generously provided by MR Popoff (Institute Pasteur, Paris, France). The exoenzyme C3 was a kind gift from P Boquet (INSERM U452, Nice, France).

CNF1 was used at the final concentration of $10^{-10} \mathrm{M}, \mathrm{CdB}$ at $2.5 \mathrm{pg} / \mathrm{ml}$ and $\mathrm{C} 3$ at $20 \mu \mathrm{g} / \mathrm{ml}$. 


\section{Scanning electron microscopy (SEM)}

Following treatments, cells were fixed with $2.5 \%$ glutaraldehyde in $0.1 \mathrm{M}$ cacodylate buffer ( $\mathrm{pH} \mathrm{7.4)}$ at room temperature for 20 min. Following postfixation in $1 \% \mathrm{OsO}_{4}$ for $30 \mathrm{~min}$, cells were dehydrated through graded ethanols, critical point dried in $\mathrm{CO}_{2}$ and gold coated by sputtering. The samples were examined with a Cambridge 360 scanning electron microscope.

\section{Fluorescent MHC and F-actin detection}

A mouse monoclonal antibody (MF20) that recognizes the skeletal muscle $\mathrm{MHC}^{47}$ (kindly provided by D Fishman, Cornell University, New York) was used to assess terminal differentiation in $\mathrm{C} 2 \mathrm{C} 12$ cells. Cells were fixed in cold methanol:acetone $(1: 1)$ for $10 \mathrm{~min}$ and permeabilized in $0.25 \%$ Triton X-100 in PBS. Cells were then incubated with the MF20 supernatant for $30 \mathrm{~min}$ at $37^{\circ} \mathrm{C}$, followed by incubation with a fluoresceine-conjugate goat anti-mouse antibody (Cappel/ICN) diluted $1: 800$, for $30 \mathrm{~min}$ at $37^{\circ} \mathrm{C}$.

For F-actin visualization, cells were fixed in 3.7\% paraformaldehyde in PBS (pH 7.4) for 10 min and permeabilized in $0.25 \%$ Triton X-100 in PBS for $5 \mathrm{~min}$. Cells were stained with fluoresceine-conjugate phalloidin (Sigma) used at the final concentration of $0.5 \mu \mathrm{g} / \mathrm{ml}$ for $30 \mathrm{~min}$ at $37^{\circ} \mathrm{C}$.

Nuclei were stained with $0.2 \mu \mathrm{g} / \mathrm{ml} \mathrm{DAPI}$ dye (Sigma) for $3 \mathrm{~min}$ at room temperature.

\section{Protein extraction and Western blot}

Cells were lysed in boiled Sample Buffer $1 \times(50 \mathrm{mM}$ Tris-HCl pH 6.8, 2\% SDS, $10 \%$ glycerol, $100 \mathrm{mM}$ DTT). In total, $25 \mu \mathrm{g}$ of total protein extracts were resolved on 8 or $12 \%$ SDS-PAGE (according to the different molecular weights) and electrically transferred onto nitrocellulose membranes. Membranes were blocked with TBS-T $(20 \mathrm{mM}$ Tris- $\mathrm{HCl}(\mathrm{pH}$ 7.4), $150 \mathrm{mM} \mathrm{NaCl}, 0.02 \%$ Tween-20) containing 5\% skimmed milk (BIO$\mathrm{RAD}$ ), for $30 \mathrm{~min}$ at room temperature, and then incubated overnight at $4{ }^{\circ} \mathrm{C}$ with primary antibodies diluted in TBS-T containing $2 \%$ milk. The following antibodies were used: monoclonal anti-MHC antibody MF20 (Bader et al. ${ }^{47}$; a kind gift of D Fishmann), $1: 10$; monoclonal antimyogenin antibody IF5D (Wright et al. ${ }^{48}$; made available by G Cossu), $1: 5$; rabbit polyclonal anti-MyoD antibody, R3B2, diluted 1:1000 (raised in collaboration with S Alemà, ICB, CNR, Rome, Italy and M Crescenzi, ISS, Rome, Italy, against murine MyoD expressed in bacteria); mouse monoclonal anti $\beta$-tubulin (ICN) diluted 1:5000. After extensive washing, immunecomplexes were detected with horse-radish peroxidase conjugated species-specific secondary antibodies (BIO-RAD) followed by enhanced chemiluminescence reaction (Amersham).

\section{Activated Rho GTPase pull-down}

Pull-down assay was performed as previously described. ${ }^{49,50}$ Cells were lysed in: (i) $50 \mathrm{mM}$ HEPES ( $\mathrm{pH} 7.4$ ), 0.5\% sodium deoxycholate, $1 \%$ $\mathrm{NP} 40,0.1 \% \mathrm{SDS}, 0.5 \mathrm{M} \mathrm{NaCl}, 10 \mathrm{mM} \mathrm{MgCl}_{2}$, plus protease inhibitors (to detect Rho-GTP); or (ii) $50 \mathrm{mM}$ HEPES (pH 7.3), $0.1 \mathrm{M} \mathrm{NaCl}, 10 \mathrm{mM}$ $\mathrm{MgCl}_{2}, 5 \%$ glycerol, $1 \% \mathrm{NP} 40,10 \mathrm{mM} \mathrm{NaF}$, plus protease inhibitors (to detect Rac/Cdc42-GTP). The cleared lysates were incubated with $80 \mu \mathrm{g}$ of GST-PAK-CD (for Rac/Cdc42) and GST-Rhotekin (for Rho) fusion proteins, bound to glutathione-coupled Sepharose beads (Amersham) for 40 min at $4^{\circ} \mathrm{C}$. Beads were washed three times in: (i) $50 \mathrm{mM} \mathrm{HEPES} \mathrm{(pH}$ 7.4), $0.5 \%$ sodium deoxycholate, $1 \% \mathrm{NP} 40,0.1 \% \mathrm{SDS}, 0.25 \mathrm{M} \mathrm{NaCl}$, $5 \mathrm{mM} \mathrm{MgCl}_{2}$, plus protease inhibitors (for Rho); or (ii) $50 \mathrm{mM} \mathrm{HEPES} \mathrm{(pH}$ 7.3), $0.1 \mathrm{M} \mathrm{NaCl}, 10 \mathrm{mM} \mathrm{MgCl}_{2}, 5 \%$ glycerol, $0.5 \% \mathrm{NP} 40,10 \mathrm{mM} \mathrm{NaF}$, plus protease inhibitors (for $\mathrm{Rac} / \mathrm{Cdc} 42$ ). The bound proteins were eluted in Sample buffer before being subjected to SDS-PAGE and immunoblotting with the following specific antibodies: polyclonal anti-RhoA (Santa Cruz Biotecnology) 1:1000, monoclonal anti-Rac1 (Transduction Laboratories) 1:3500 and monoclonal anti-Cdc42 (Santa Cruz Biotecnology) $1: 500$. Whole-cell lysates ( $2 \%$ of input) were analyzed in parallel.

Autoradiographs, scanned using the Imaging Densitometer GS-700 (BIO-RAD), were quantified by means of Multianalist software and normalized as a function of the total proteins loaded in the assay.

\section{Northern blot analysis}

Total RNA was prepared and analyzed as described. ${ }^{51}$ For detection of muscle-specific and constitutive transcripts, inserts were excised with the appropriate restriction enzymes from the following plasmids and used as probes: pMHC-25, containing a $0.6 \mathrm{~kb} \mathrm{cDNA}$ fragment encoding the mouse skeletal MHC (kindly provided by D Fishman, Cornell University, New York); pEMC11S containing a $1.5 \mathrm{~kb}$ mouse MyoD cDNA (obtained from $\mathrm{H}$ Weintraub); pEMSV-mgn, containing a $1.5 \mathrm{~kb} \mathrm{cDNA}$ fragment encoding the rat Myogenin ${ }^{48}$ (made available by $V$ Sorrentino); a plasmid containing a $1.2 \mathrm{~kb}$ cDNA fragment of the avian glyceraldehyde-3phosphate-dehydrogenase (GAPDH) (obtained from C Schneider, CIB, Trieste, Italy).

\section{Acknowledgements}

We are grateful to W Malorni for critical reading of the manuscript and useful suggestions and to MG Quaranta for the densitometry analysis. The work has been partially supported by grants from ISS (project 'Bacterial protein toxins as pharmacological agents that act on muscle cell differentiation') to CF and from CNR/MIUR (project 'Biomolecole per la salute umana') and University of Rome 'La Sapienza' to MG.

\section{References}

1. Molketin JD and Olson E (1996) Defining the regulatory networks for muscle development. Curr. Opin. Genet. Dev. 6: 445-453

2. Perry LS and Rudnicki MA (2000) Molecular mechanisms regulating myogenic determination and differentiation. Front. Biosci. 5: 750-767

3. Lassar AB, Buskin JN, Lockshon D, Davis RL, Apone S, Hauschka SD and Weintraub H (1989) MyoD is a sequence-specific DNA binding protein requiring a region of myc homology to bind to the muscle creatine kinase enhancer. Cell 58: 823-831

4. Maione R and Amati $P$ (1997) Interdependence between muscle differentiation and cell-cycle control. Biochim. Biophys. Acta 1332: M19-M30

5. Walsh K and Perlman $\mathrm{H}$ (1997) Cell cycle exit upon myogenic differentiation. Curr. Opin. Genet. Dev. 7: 597-602

6. Wei $Q$ and Paterson BM (2001) Regulation of MyoD function in the dividing myoblast. FEBS Lett. 490: 171-178

7. Etienne-Manneville $S$ and Hall $A$ (2002) Rho GTPases in cell biology. Nature 420: 629-635

8. Carnac G, Primig M, Kitzmann M, Chafey P, Tuil D, Lamb N and Fernandez A (1998) RhoA GTPase and serum response factor control selectively the expression of MyoD without affecting Myf5 in mouse myoblasts. Mol. Biol. Cell 9: 1891-1902

9. Wei L, Wei Z, Croissant JD, Johansen F-E, Prywes R, Balasubramanyam A and Schwartz RJ (1998) RhoA signaling via serum response factor plays an obligatory role in myogenic differentiation. J. Biol. Chem. 273: 30284-30287

10. Gallo R, Serafini M, Castellani L, Falcone G and Alemà S (1999) Distinct effects of Rac1 on differentiation of primary avian myoblasts. Mol. Biol. Cell 10: $3137-3150$ 
11. Meriane M, Roux P, Priming M, Fort $P$ and Gauthier-Rouviere $C$ (2000) Critical activities of Rac1 and $\mathrm{Cdc} 42 \mathrm{Hs}$ in skeletal myogenesis: antagonistic effects of JNK and p38 pathways. Mol. Biol. Cell 11: 2513-2528

12. Heller H, Gredinger E and Bengal E (2001) Rac1 inhibits myogenic dufferentiation by preventing the complete withdrawal of myoblasts from the cell cycle. J. Biol. Chem. 276: 37307-37316

13. Takano H, Komuro I, Oka T, Shiojima I, Hiuroi Y, Mizuno T and Yazaki Y (1998) The Rho family $G$ proteins play a critical role in muscle differentiation. Mol. Cell. Biol. 18: 1580-1589

14. Fiorentini C, Gauthier M, Donelli $G$ and Boquet $P$ (1998) Bacterial toxins and the Rho GTP-binding protein: what microbes teach us about cell regulation. Cell Death Differ. 5: 720-728

15. Flatau $G$, Lemichez $E$, Gauthier $M$, Chardin $P$, Paris $S$, Fiorentini $C$ and Boquet $P$ (1997) Toxin-induced activation of the $G$ protein p21 Rho by deamidation of glutamine. J. Biol. Chem. 272: 19532-19537

16. Schmidt G, Sher P, Wilm M, Selzer J, Mann M and Aktories K (1997) Gln 63 of Rho is deamidated by Escherichia coli cytotoxic necrotizing factor-1. Nature 387: 725-729

17. Lerm M, Schmidt G, Goehring UM, Schirmer J and Aktories K (1999) Identification of the region of Rho involved in substrate recognition by Escherichia coli cytotoxic necrotizing factor 1 (CNF1). J. Biol. Chem. 274: 28999-29004

18. Fiorentini C, Falzano L, Fabbri A, Stringaro A, Logozzi M, Travaglione S, Contamin S, Arancia G, Malorni W and Fais S (2001) Activation of Rho GTPases by cytotoxic necrotizing factor 1 induces macropinocytosis and scavenging activity in epithelial cells. Mol. Biol. Cell 12: 2061-2073

19. Doye A, Mettouchi A, Bossis G, Clement R, Buisson-Touati C, Flatau G, Gagnoux L, Piechaczyk M, Boquet P and Lemichez E (2002) CNF1 exploits the ubiquitin-proteasome machinery to restrict Rho GTPase activation for bacterial host cell invasion. Cell 111: 553-564

20. Malorni W, Quaranta MG, Straface E, Falzano L, Fabbri A, Viora M and Fiorentini C (2003) The Rac-activating toxin cytotoxic necrotizing factor 1 oversees NK cell-mediated activity by regulating the actin/microtubule interplay. J. Immunol. 171: 4195-4202

21. Fiorentini C, Fabbri A, Flatau G, Donelli G, Matarrese $P$, Lemichez E, Falzano L and Boquet $P$ (1997) Escherichia coli cytotoxic necrotizing factor 1 (CNF1), a toxin that activates the Rho GTPase. J. Biol. Chem. 272: 19532-19537

22. Crescenzi M, Crouch DH and Tatò F (1994) Transformation by myc prevents fusion but not biochemical differentiation of $\mathrm{C} 2 \mathrm{C} 12$ myoblasts: mechanisms of phenotypic correction in mixed culture with normal cells. J. Cell Biol. 125: $1137-1145$

23. Russo S, Tomatis D, Collo G, Tarone $G$ and Tatò $F$ (1998) Myogenic conversion of $\mathrm{NIH} 3 \mathrm{~T} 3$ cells by exogenous MyoD family members: dissociation of terminal differentiation from myotube formation. J. Cell Sci. 111: 691-700

24. Hollenberg SM, Cheng PF and Weintraub H (1993) Use of a conditional MyoD transcription factor in studies of MyoD trans-activation and muscle determination. Proc. Natl. Acad. Sci. USA 90: 8028-8032

25. Essler M, Linder S, Scell B, Hufner K, Wiedemann A, Randhahn K, Staddon JM and Aepfelbacher M (2003) Cytotoxic necrotizing factor 1 of Escherichia coli stimulates Rho/Rho-kinase-dependent myosin light-chain phosphorylation without inactivating myosin light-chain phosphatase in endothelial cells. Infect. Immun. 71: 5188-5193

26. Moreau V, Tatin F, Varon $C$ and Genot E (2003) Actin can reorganize into podosomes in aortic endothelial cells, a process controlled by Cdc42 and RhoA. Mol. Cell. Biol. 23: 6809-6822

27. Charrasse $S$, Meriane M, Comunale F, Blangy $A$ and Gauthier-Rouviere $C$ (2002) N- cadherin-dependent cell-cell contact regulates Rho GTPases and beta-catenin localization in mouse C2C12 myoblasts. J. Cell Biol. 158: 935-965

28. Just I, Selzer J, Wilm M, von Eichel-Streiber C, Mann M and Aktories K (1995) Glucosylation of Rho proteins by Clostridium difficile toxin B. Nature 375 : 500-503

29. Genth H, Gerhard R, Maeda A, Amano M, Kaibuchi K, Aktories K and Just I (2003) Entrapment of Rho ADP-ribosylated by Clostridium botulinum C3 exoenzyme in the Rho-guanine nucleotide dissociation inhibitor-1 complex. J. Biol. Chem. 278: 28523-28527
30. Ridley AJ and Hall A (1992) The small GTP-binding protein rho regulates the assembly of focal adhesions and actin stress fibers in response to growth factors. Cell 70: 389-399

31. Ridley AJ, Paterson HF, Johnston CL, Diekmann D and Hall A (1992) The small GTP-binding protein rac regulates growth factor-induced membrane ruffling. Cell 70: $401-410$

32. Sander EE, ten Klooster JP, van Delft S, van der Kammen RA and Collard JG (1999) Rac downregulates Rho activity: reciprocal balance between both GTPases determines cellular morphology and migratory behavior. J. Cell Biol. 147: 1009-1022

33. Luo L (2000) Rho GTPases in neuronal morphogenesis. Nat. Rev. Neurosci. 1: $173-180$

34. Noren NK, Niessen CM, Gumbiner BM and Burridge K (2001) Cadherin engagement regulates Rho family GTPases. J. Biol. Chem. 276: 33305-33308

35. Arthur WT, Petch LA and Burridge K (2000) Integrin engagement suppresses RhoA activity via a c-Src-dependent mechanism. Curr. Biol. 10: 719-722

36. Arthur WT and Burridge K (2001) RhoA inactivation by $p 190$ RhoGAP regulates cell spreading and migration by promoting membrane protrusion and polarity. Mol. Biol. Cell 12: 2711-2720

37. van Leeuwen FN, van Delft S, Kain HE, van der Kammen RA and Collard JG (1999) Rac regulates phosphorylation of the myosin-II heavy chain, actinomyosin disassembly and cell spreading. Nat. Cell Biol. 1: 242-248

38. Weston C, Gordon C, Teressa G, Hod E, Ren XD and Prives J (2003) Cooperative regulation by Rac and Rho of agrin-induced acetylcholine receptor clustering in muscle cells. J. Biol. Chem. 278: 6450-6455

39. Meriane M, Charrasse S, Comunale F and Gauthier-Rouviere C (2002) Transforming growth factor beta activates Rac1 and Cdc42Hs GTPases and the JNK pathway in skeletal muscle cells. Biol. Cell 94: 535-543

40. Luo L, Liao YJ, Jan LY and Jan YN (1994) Distinct morphogenetic functions of similar small GTPases: Drosophila Drac1 is involved in axonal outgrowth and myoblast fusion. Genes Dev. 8: 1787-1802

41. Boyer L, Travaglione S, Falzano L, Gauthier NC, Popoff MR, Lemichez E, Fiorentini C and Fabbri A (2004) Rac GTPase instructs Nuclear Factor-kB activation by conveying the SCF complex and $\mathrm{lkB} \alpha$ to the ruffling membranes. Mol. Biol. Cell 15: 1124-1133

42. Sordella R, Jiang W, Chen G-C, Curto M and Settleman J (2003) Modulation of Rho GTPase signaling regulated a switch between adipogenesis and myogenesis. Cell 113: 147-158

43. Kontaridis Ml, Eminaga S, Fornaro M, Zito $\mathrm{Cl}$, Sordella $\mathrm{R}$, Settleman $\mathrm{J}$ and Bennett AM (2004) SHP-2 positively regulates myogenesis by coupling to the Rho GTPase signalling pathway. Mol. Cell. Biol. 24: 5340-5352

44. Joneson T, McDonough M, Bar-Sagi D and Van Aelst L (1996) Rac regulation of actin polymerization and proliferation by a pathway distinct from Jun kinase. Science 274: 1374-1376

45. Lamarche N, Tapon N, Stowers L, Burbelo PD, Aspenstrom P, Bridges T, Chant J and Hall A (1996) Rac and Cdc42 induce actin polymerization and G1 cell cycle progression independently of p65PAK and the JNK/SAPK MAP kinase cascade. Cell 87: 519-529

46. Falzano L, Fiorentini C, Donelli G, Michel E, Kocks C, Cossart P, Cabanie L, Oswald $E$ and Boquet $P$ (1993) Induction of phagocytic behaviour in human epithelial cells by Escherichia coli cytotoxic necrotizing factor type 1. Mol. Microbiol. 9: 1247-1254

47. Bader D, Masaki T and Fischman DA (1982) Immunochemical analysis of myosin heavy chain during avian myogenesis in vivo and in vitro. J. Cell. Biol. 95: $763-770$

48. Wright WE, Sasoon DA and Lin WK (1989) Myogenin, a factor regulating myogenesis, has a domain homologous to MyoD. Cell 56: 607-617

49. Sander EE, van Delft S, ten Clooster JP, Reid T, van der Cammen RA, Michiels F and Collard JG (1998) Matrix-dependent Tiam1/Rac signaling in epithelial cells promotes either cell-cell adhesion or cell migration and is regulated by phosphatidilynositol 3-kinase. J. Cell Biol. 143: 1385-1398

50. Ren XD, Kiosses WB and Schwartz MA (1999) Regulation of the small GTPbinding protein Rho by cell adhesion and the cytoskeleton. EMBO J. 18: 578-585

51. Russo S, Tatò $F$ and Grossi M (1997) Transcriptional down-regulation of myogenin expression is associated with v-ras-induced block of differentiation in unestablished quail muscle cells. Oncogene 14: 63-73 